\title{
Problems and countermeasures on the safety of rainwater harvesting for drinking in China
}

\author{
Liu Laisheng, Liu Linghua, Wu Leixiang, Wu Jiapeng and Huo Weijie \\ China Institute of Water Resources and Hydropower Research, Beijing 100038, China
}

\begin{abstract}
China is increasingly confronted with serious water shortages, so rainwater harvesting and utilization have gradually received attention with advantages such as accessibility, simple operation and low cost. The harvested rainwater can be used for drinking, irrigation, municipal greening, etc., and when applied for drinking, the demand for water quality is highest. Most existing researches have put their focus on improving the accumulation of rainwater, but there is a lack of in-depth studies on how to enhance the quality of rainwater. Based on the above considerations, this paper, by summing up the situation of rainwater harvesting and utilization in China, has systematically analyzed the system components of rainwater harvesting for drinking, i.e., the consisting units of rainwater harvesting, delivering, processing and accumulating. It also explains the sources of rainwater pollution and how to deal with it. Considering that the water harvesting system can make a contribution to the society and public welfare, this paper proposes a framework of participatory management for projects of rainwater harvesting for drinking.
\end{abstract}

\section{Current practice of rainwater harvesting and drinking in china and abroad}

\subsection{Current practice of rainwater harvesting and drinking in foreign countries}

In countries outside China, "rainwater utilization" is usually referred to as "rainwater management". From the beginning of the 1980s, the world began to explore how to utilize rainwater resources. At present, many countries in the world have recognized the value of using rainwater, and adopted a variety of technologies, equipments and measures for rainwater harvesting, application, control and management. In recent years, different scales of researches and applications on rainwater utilization and management have been carried out in more than 40 countries and regions such as the United States, Canada, France, India, Israel and Japan. In Australia's rural and suburban areas where houses are near, round sumps made of corrugated steel plates are commonly established to collect the rainwater from roofs. In many parts of Kenya in Africa, UNDP and the World Bank take rainwater storage tanks as an essential part of their Projects on Rural Water Supply and Sanitation. Later, such technique is spread to Botswana, Namibia, Tanzania and other places, leading to the development of African's rainwater harvesting project. In Latin America, Mexico and Brazil have also made a prevailing utilization of rainwater: In Mexico, there is relative mature system for rainwater harvesting on Chiapass plateau, and the system consists of aluminum roofs, trapezoidal underground pools, pool filters, pumps, etc.; In northeastern Brazil, poor people who lives in the semi-arid regions near the equator have built more than 2,000 water storage tanks by fence cement, precast concrete panels, lime and bricks under the fund of Canada and other international organizations.

Many countries and regions have introduced corresponding technical manuals, specifications and standards. They developed a series of laws and regulations on the utilization of rainwater as a support, e.g., Germany's Federal Water Act, Building Regulations and Local Regulations, and they all take the form of legal provisions to strengthen the protection of the natural environment and the sustainable use of water, such as the rule of requiring the owner of new projects to dispose and utilize rainwater.

\subsection{Current practice of rainwater harvesting and drinking in China}

China's water resource is averaged as $2300 \mathrm{~m}^{3}$ per capita, only $1 / 4$ of the world's per capita consumption. Such number is ranked 109 in the world, so China was listed as one of the world's 13 water-anemia countries. As rainwater harvesting benefits so much, the development and utilization of rainwater resources has achieved considerable development in recent years. Broadly speaking, rainwater harvesting and utilization has the following advantages: 1). Reducing Investment. China's rural and mountainous area is so vast that water users are relatively scattered, therefore long-distance water pipelines are needed for centralized water supply, which 
hugely increases the construction costs. 2). Saving energy. Long distance results in large water head loss, so it requires higher pump head with huge energy consumption. 3). Conserving water. The centralized water supply by existing plants in rural areas is mostly sourced from surface water or groundwater, such as rivers, lakes and reservoirs, so rainwater accumulation can effectively reduce the extraction of surface water and groundwater. 4). Reducing the erosion by rainstorm. Distributed rainwater harvesting can lessen the intensity of runoff and reduce the erosion by rainwater to the runoff-collecting surface, thereby reducing soil erosion.

In China, rainwater harvesting and utilization is mainly applied to the following types of water-deficient areas: 1). Water-deficient areas with a lack of resource. In arid and semi-arid areas such as Gansu and central Ningxia, the rainfall is only $200-400 \mathrm{~mm}$ while the evaporation is over $1000 \mathrm{~mm}$, and no surface water and groundwater sources are available in these areas; 2). Seasonal water-deficient areas. In China's Fujian, Guizhou, Hubei and other hilly areas, there is abundant rainfall but with large seasonal variations, so waterdeficiency still occurs in winter and spring; 3). Waterdeficient areas with exploitation difficulty. In the southwest mountainous areas, the underground water is deeply buried because of deep valleys everywhere, which results in unbearable exploitation costs; 4). Waterdeficient areas with poor water quality. In these areas are featured by poor water quality which is sourced from brackish water, fluoride water, high-arsenic water, etc. In recent years, China has constructed water cellars, tanks, ponds and other miniature water conservancy projects in the above water-deficient areas as an effective solution to the problem of water shortage, but there are still problems as follows: 1). Most projects are spontaneously constructed by farmers, so rainwater cannot be effectively collected due to the deficiency of harvesting brought by unprofessional design of projects. 2). The amount of rainwater harvesting is insufficient due to inappropriate layout of projects and a lack of unified technical guidance and planning; quality concerns also occur during the construction of projects, e.g., problems of cellars range from leaking to collapsing. 3). Lack of protection and pollution control measures in areas of rainwater resources. 4).Short of supporting policies. 5). Lack of professional technical atlas, standards and norms. 6).Drinking water is not safe for users due to a lack of effective rainwater treatment facilities.

\section{System components of rainwater harvesting for drinking}

The system of rainwater harvesting for drinking mainly includes four component units that respectively related to processes of harvesting, storing, processing and delivering. Figure 1 shows the system components of rainwater harvesting for drinking.

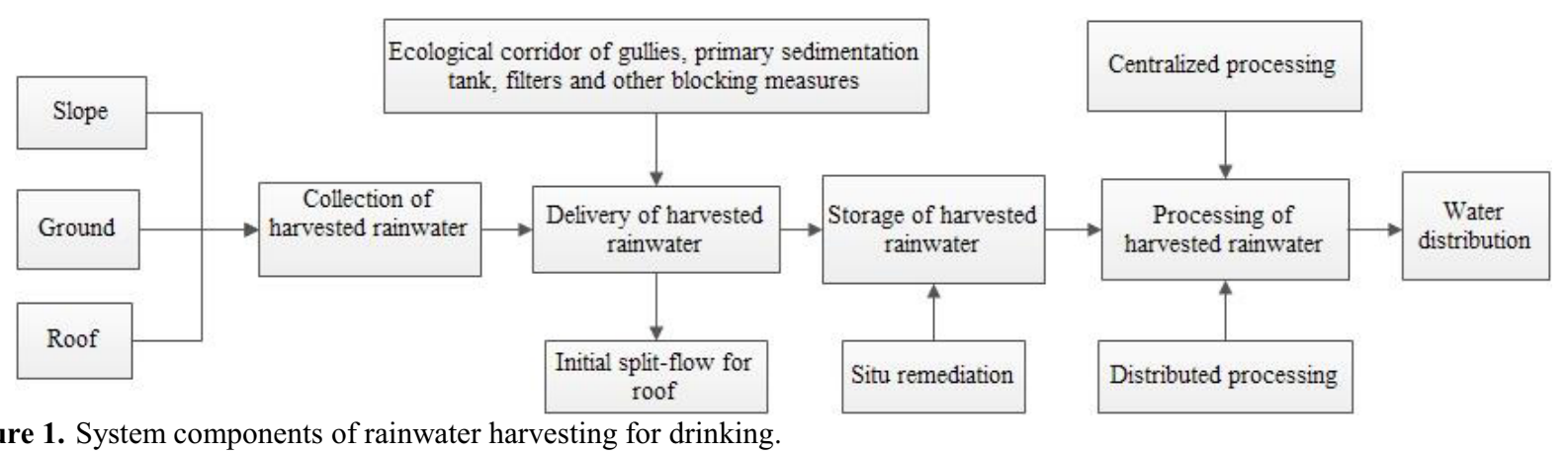

\subsection{Collecting units for rainwater harvesting}

\subsubsection{Types of runoff-collecting surfaces}

Rainwater Harvesting and Utilization Project takes it as a priority to solve the problem of rainwater harvesting and storage. A rational, efficient and high-quality collection of rainfall runoff is regarded as the main objective of rainwater harvesting. In present China, roofs are mainly adopted as runoff-collecting surfaces, and some other areas also take hardened concrete patio floors to fulfill this function. runoff-collecting surfaces basically include three types: existing runoff-collecting surface, specialized runoff-collecting surface and natural runoff-collecting surface. 1). Existing runoff-collecting surface refers to the existing roofs (tile roof, concrete surface or mortar surface); 2). Specialized runoff-collecting surface refers to the hardened concrete and compacted solid in

courtyard, threshing ground and other unused venues around houses; 3).Natural runoff-collecting surface refers to the natural slopes that used as runoff-collecting surfaces. At present in China's rural areas, existing and specialized runoff-collecting surfaces are most frequently adopted, and the surface area is based on average annual rainfall, rainfall characteristics, water demand planning and water consumption criteria.

\subsubsection{Material of runoff-collecting surface}

The material of runoff-collecting surface reflects one of the key technologies for projects of rainwater harvesting and utilization. In northwest China, a variety of ways are adopted to deal with runoff-collecting surfaces for rainwater harvesting projects, e.g., concrete, HEC solidified soil, AAM cement soil, compacted cement soil, cement tile, compacted 37 lime earth, plastic film, glassfiber linoleum, chemical material handling and original soil rammed, etc. Concrete is one of the most commonly 
used material for runoff collecting with an efficiency of above $80 \%$. HEC solidified soil functions as a curing agent that increases soil strength and impermeability. It takes industrial waste as its raw material, and is carefully mixed with core materials and other components to become a kind of cementing materials without clinker.

\subsection{Delivery units for harvested rainwater}

Different scholars give different definitions on initial discarded rainwater. Geiger (1987) defines it as "the largest proportion of pollution load in initial runoff" [1]; Saget (1996) defines the initial discarded as "30\% of the initial runoff that contains $80 \%$ of pollution load"[2]. Factors with an impact on initial discarded rainwater include the followings: rainfall duration, rainfall amount, rainfall intensity, interval between two rainfalls, types of runoff-collecting surfaces, pollution sources and extent, etc. Figure 2 shows a typical attenuation of concentrations of pollutants in harvested rainwater. As the rain continues, the concentration of pollutants in rainwater is gradually reduced from L0 until the end of rainfall. Ding Kunlun, et al (2011) made a study on roofharvested rainwater in some rural area located in Beijing suburb. The results show that, from the start of rainfall, the concentration of pollutants in roof-harvested rainwater showed a gradual downward trend. The initial rainfall had obvious scouring action. When the amount of rainfall reached $2-3 \mathrm{~mm}, 90 \%$ of contaminants in rainwater could be effectively removed and permanganate index was reduced by $40 \%$ [3]. According to the "Technical Specifications on Rainwater Utilization Project for Architecture and Community" (GB504002006 ), if the amount of rainfall is less than $10 \mathrm{~mm}$ in Beijing, $2 \mathrm{~mm}$ of the initial roof-harvested runoff contains more than $70 \%$ of the pollutants. The amount of initial discarded rainwater is determined in accordance with the permanganate index, suspended solids, chroma, etc. in rainwater, which are actually measured on the underlying surface. When there is no reference of measured data, 2$3 \mathrm{~mm}$ of runoff depth could be adopted as the amount of initial discarded rainwater for roof-harvested rainwater, and for ground-harvested rainwater, the depth will be 3$5 \mathrm{~mm}[4]$.

Foreign countries have an early study on devices for initial discarded rainwater with already approved mature products, while China has a relatively late start that confines its choice to the commonly used volumetric pool for discarded rainwater. Chen Gang et al. (2013) divided the devices for initial discarded rainwater into active ones (without mechanical power) and mechanical ones (using mechanical power) according to the discarding principles. Of which, the active devices are subdivided into volumetric devices, infiltration wells, and small-large tubes in line with the implementation of discarding rainwater. Since the volumetric discarding adopts an empirical coefficient method, the contamination of underlying surface often differs with seasons in practical engineering applications, but the volume of discarded rainwater has been fixed, so if the underlying surface has heavy contamination, the amount of discarded rainwater will not be enough. As a result, at the end of rainwater discarding, the pollutants in follow-up rainwater cannot be cleared. Yang Xiao et al (2010) designed a flap-typed separator for initial rainwater which makes use of hydraulic action to automatically flip the flap and in turn discard the initial rainwater [5]. Huang Yongqiang et al (2010) designed a set of hydrocyclone separator, which applies the combined action of gravity in cyclone separator and centrifugal force generated by vortex. The device can effectively remove the suspended solids, particulate nitrogen and particulate phosphorus. At the maximum, over $70 \%$ of SS can be removed [6]

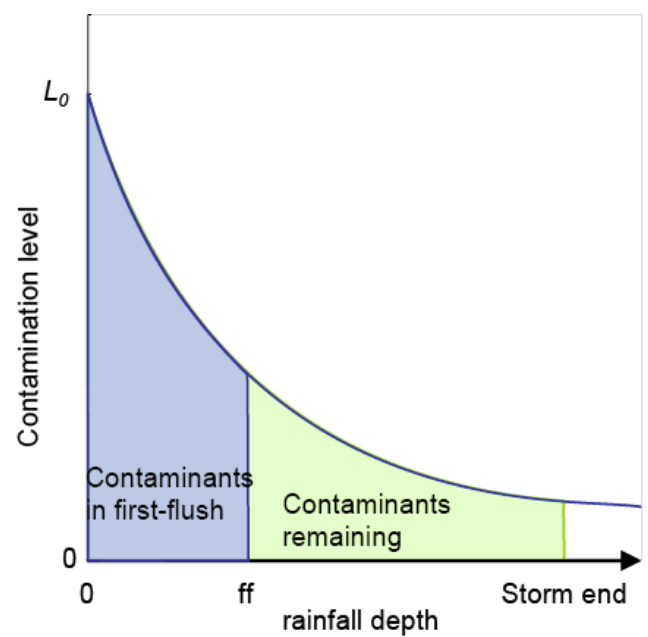

Figure 2. Pollutant concentrations in rainwater that change with rainfall duration.

\subsection{Treatment units for harvested rainwater}

In China's rural areas, residents are relatively scattered. Subject to the socio-economic and geographical conditions, conventional centralized water-plants cannot be spread in rural areas. Limited to economic conditions, knowledge levels, drinking-water safety awareness and other factors, usually farmers only make a coarse filter before storing the rainwater and adopt the process of precipitation after the storage. They rarely buy advanced devices to further treat rainwater. The so-called "coarse filter before storing rainwater and deposition after the storage" means that: Before rainwater enters into storage facilities, there are trash racks grit chamber and sand filter pool and other facilities set at water inlets to remove impurities like coarse sediments and weeds in rainwater; after the rainwater enters into storage facilities, it will be deposited and disinfected in a simple way by the added ash (potassium carbonate), alum (aluminum sulfate), "pestilence killer", etc.

Currently in rural areas, filtration technology is frequently used to treat drinking water, and ceramic filter is one of such common devices. This device has an advantage that it can be reused after the adhered contaminants are removed by a brush when being blocked, but the size of filter pores is decisive for the removal of contaminants, and such size is subject to the pressure of supplied water. With the development of technology, products of ceramic filter have been widely used in cities where tap water is available. However, as a 
drawback, ceramic filter does not apply to those rural single-household family without access to water pressure. In addition, the filter has a certain service life, and it has to be frequently replaced if water quality is poor, and that will burden water users with unbearable costs. The sandfiltering technology applied to centralized water plants can be used in rural areas after being downsized. This technology can make use of existing materials with less costs. Although most suspended solids can be removed by it, further chemical sterilization or pasteurized process have to be adopted since bacteria in the effluent are still out of limits. In recent years, more urban water users begin to use small-scale integrated water purification equipment, such equipment adopts ceramic filter, PP cotton, activated carbon, resin fiber as media for filtering, or uses nanofiltration, microfiltration, reverse osmosis and other deep processing techniques. Such device has better effects, but costly and complex to operate, and the charges for water and electricity generated during operation and backwash hinder its application in rural areas. The technology of slow biological filtration has been piloted in rural areas of Hubei, Fujian, Sichuan, Guangxi and other places in China and received recognition by the majority of water users because of its simple operation and maintenance, low cost of water system, and such water can be safely drunk without applying chemical disinfection for the effluents.

\subsection{Storage units for harvested rainwater}

Rainwater storage system mainly includes water cellars (assembled, bottle-shaped, cylindrical, spherical, tureentyped, kiln-typed, cup-typed water cellars), ponds, tanks, flood pools, ponds and other water storage facilities. The most widely used rainwater storage facilities are mortarsurface water cellars, concrete pools and other masonry pools. In North China, mortar surface is usually applied for water cellars, and reservoirs are concrete-pouring (brick reservoir tends to crack in winter); while in some rocky areas of southern China, stones are easily accessible, so reservoirs are mainly built by stones. The above rainwater storage facilities are generally built around residential areas near farmers' houses for harvesting rainwater from roofs, patios and yards rainwater to meet the needs for domestic water. The volume of rainwater storage facilities is determined by the probability of water supply considering the water inflow and consumption. In loess regions of northern China, the volume of mortar-surface cellar is generally $30 \mathrm{~m}^{3}$, and that of concrete pool is generally between 30 $50 \mathrm{~m}^{3}$; while in rocky areas of southern China, the volume of masonry tank is generally above $50 \mathrm{~m}^{3}$, but some can be up to about $100 \mathrm{~m}^{3}$.

\section{Protection to avoid pollution of rainwater}

The cellars, tanks, trenches and other small projects for rainwater harvesting in China have played an important role in solving the problem of water shortage, but there is not enough attention attached to water quality. In the process of landing and runoff, rainwater runoff is easily polluted by atmospheric deposition, surface-sourced fertilizers and pesticides, solid debris and waste on runoff-collecting surface (garbage, animal manure, etc.) and other pollutants caused by human activities, so the water quality is worrisome. If being drunk without treatment, such rainwater would produce great harm to humans and animals. Pre-filtration system is capable of intercepting some large particles of stones, twigs, leaves, but small particles and bacteria attached there as well as organic matters will penetrate filters and enter into reservoirs. Extensive survey data indicate that, waterborne typhoid, dysentery, hepatitis and diarrhea are still the main intestinal infectious diseases in rural China. If people drink untreated rainwater directly, they could suffer from health risks including bacterial diarrhea (Salmonella and Campylobacter), bacterial pneumonia (Legionella), botulism (Clostridium), Giardia and Cryptosporidium diarrhea.

Pollution of water in reservoirs comes mainly from the processes of harvesting, using and storing water. The main protective measures include: 1) Protective measures against pollution during rainwater harvesting. i). Protection for the source of harvested rainwater. Area of runoff-collecting surface should be protected from the pollution of livestock, manure, garbage and stacking wood. Around the runoff-collecting surface, there should be facilities to prevent rainwater entering from other convergence areas. ii). Cleaning of rainwater harvesting structures. The scope of cleaning involves rainwaterharvesting surfaces and tanks, sink drains, grit chambers and filters. iii). Rainwater discarding devices for initial stage. If economically permitted, rainwater discarding devices for initial stage could be installed. Otherwise, the reservoir inlet should be blocked at the beginning of rainfall. It can be opened for water storage after the rainwater of initial 3-5min is discarded. 2) Precautions against pollution during storage. i). Reservoir protection. Reservoirs should adopt underground or semiunderground structure to reduce water temperature. They can be covered to reduce external contamination, avoid sunlight, and prevent algae from growing within. Bottom sediments should be cleaned regularly to reduce secondary pollution to water by pollutants in sediments. ii). Disinfection by chemical agents. In case of high turbidity during flood season in summer, simple disinfection and sedimentation should be applied for water by adding chemical agents like alum (aluminum sulfate), lime, basic aluminum chloride. 3) Measures against the pollution during getting and drinking water. i). If economically permitted, it would be better to use a hand pump or submersible pump to directly draw water into a storage tank/bucket; otherwise, the traditional way of getting water should be improved, and water should be taken by a fixed bucket to avoid pollution coming from ground, crowd and livestock. For temporary storage tank/bucket in kitchen, it should be covered to keep away insects, rats and mosquitoes. ii). Adopting the way of supplying water by quality degrades applied in cities, roof-harvested rainwater and courtyard/slope rainwater are stored in different reservoirs to avoid crosscontamination. Roof-harvested rainwater is for drinking, 
while patio/slope rainwater is for livelihood using. iii). Construct two reservoirs or more to alternately use them for water storage, so there would be settlement time for reservoirs to prevent the relatively clear water from secondary disturbance.

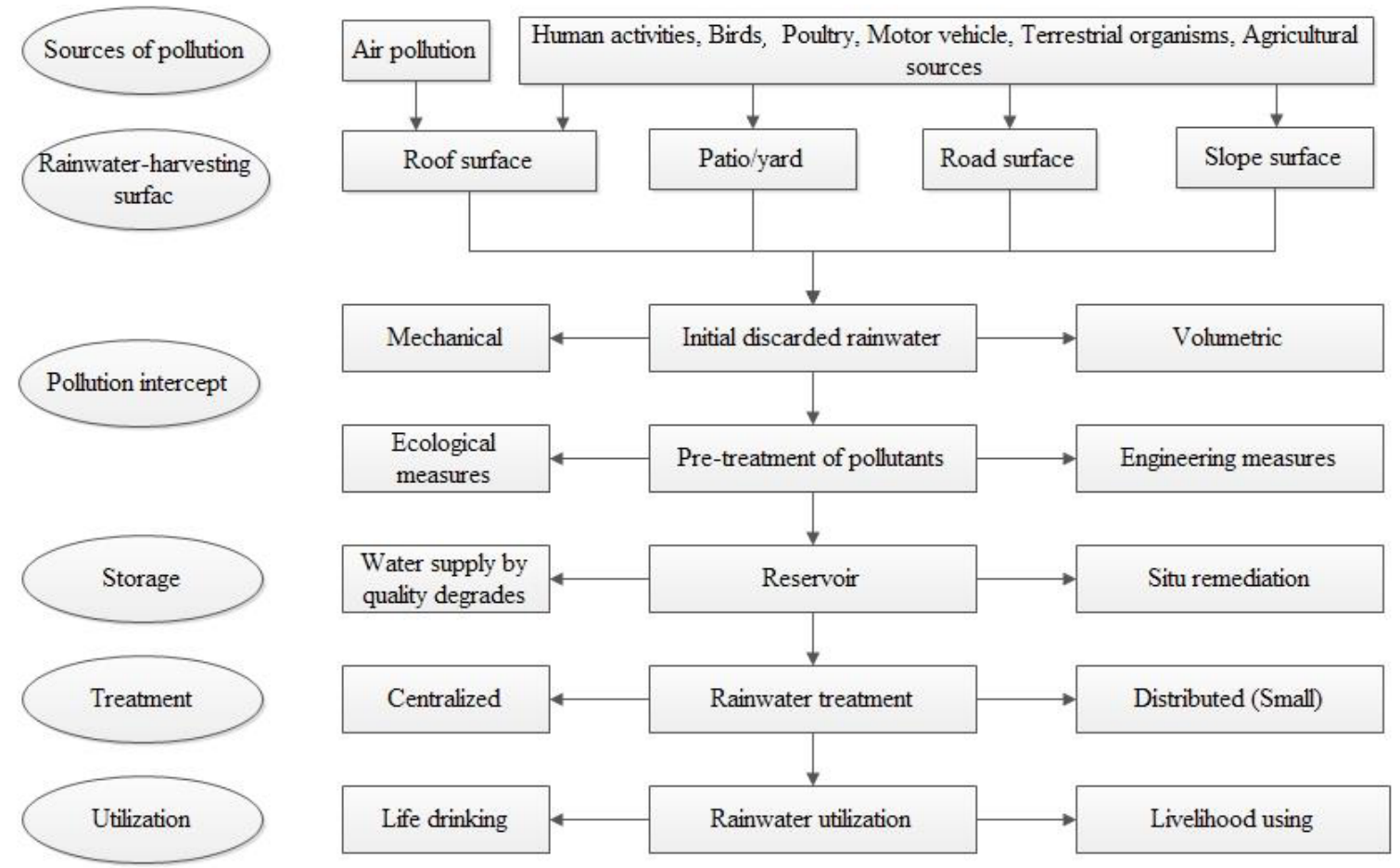

Figure 3. Pollution sources of harvested rainwater and processes of treatment units.

\section{Maintenance and management on the system of rainwater harvesting for drinking}

The property is owned by individuals as to the singlehousehold decentralized engineering of rainwater harvesting for drinking. Due to the limit of knowledge, farmers are short of specialized skills for system construction, initial pollutant interception, further rainwater treatment and subsequent operation and maintenance. Therefore, the safety of distributed rainwater harvesting for drinking will be subject to the problems of how to technically guide these water users to improve the efficiency of rainwater harvesting system, how to maximize the interception of pollutants in rainwater and how to ensure a stable effect of further rainwater treatment system.
As a way of water supply in rural areas, the small centralized system of rainwater harvesting for drinking is beneficial for the society and public. Domestic and international practice shows that, the mechanism of participatory management runs a successful way to safeguard an effective supply of rural public goods. Under the framework of participatory mechanism, government should change its role to create a favorable environment for participatory management, so that enterprises and water-using associations will assume the responsibility of water supply. Government is responsible for the protection of water sources and public advocacy $\&$ training. Enterprises provide management, operation and maintenance according to contracts signed with the water-using communities. Water-using associations are in charge of collecting water bills. In this way, a framework of interaction for sustainable development will be constructed as shown in Figure 4.

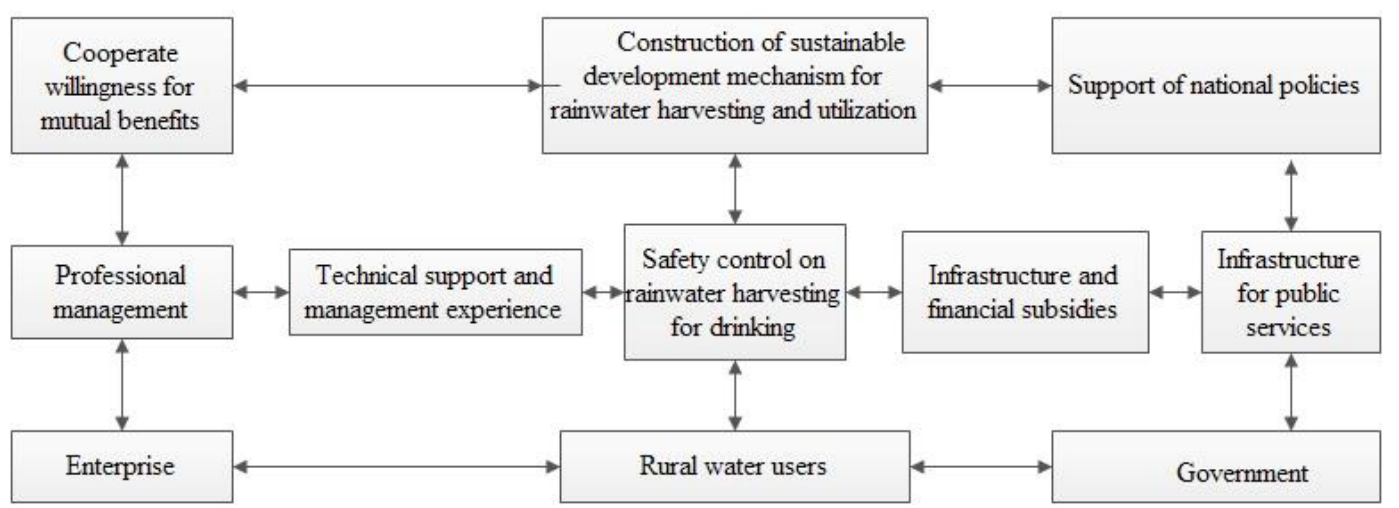

Figure 4. Framework of participatory management on project of rainwater harvesting for drinking in rural areas. 


\section{Conclusion}

With China's social and economic development by leaps and bounds, the contradiction between social-economic growth and the carrying capacity of water resources and water environment becomes so increasingly prominent that it has aroused great attention of the country. In the "Views on Implementing the Most Stringent Water Management System" (National issue [2012] No.3) issued by the State Council, "three red lines" are explicitly put forward to administer the development and utilization of water resources, control the efficiency of water use, and prevent pollution in water functional areas. In current China, there is no new water source for development while existing sources are suffering from external contamination. Worse still, some sources are gradually shrinking and facing the risks of depletion along with increased imbalance between supply and demand. Confronting with problems like water scarcity, increasing water demand and deteriorating water quality, it would be of great significance to consider how to build a water conservation culture, maintain sustainable use of water resources, restore a healthy cycle of natural water, further tap the potential of rainwater resource for utilization, improve the efficiency of rainwater harvesting, and work on the research and development of appropriate technology for rainwater harvesting.

\section{Acknowledgment}

We would like to thank the National Science \& Technology Pillar Program during the 12th Five-year Plan Period (2012BAJ21B03) for the financial support to this study.

\section{References}

1. W. Geiger, Flushing effects in combined sewer systems, Proceeding of the 4th Int.Cont.on Urban Drainage, Lausanne, Switzerland, (1987), 40-46

2. A. Saget, G. Chebbo, J.-L. Bertrand-Krajewski, The first flush in sewer systems, Water Science and Technology, 33(9), 101-108, (1996)

3. K. Ding, W. Xie, W. Sun, Research on water quality and initial discarded amount of roof rain-off, China Rural Water and Hydropower, 1:85-88 (2011)

4. Engineering technicalcode for rain utilization in buiding and sub-district, (GB50400-2006), Beijing: China Building Industry Press, 2006.

5. X. Yang, J. Zhang, T. Li, J. Wu, Design of initial rainwater split-flow instrument by reversing board[J]. Journal of Water Resources \& Water Engineering, 21(6):121-124 (2010)

6. Y. Huang, T. $\mathrm{Wu}$, Initial Splitflow/Hydrocyclone/Eco-floating Bed for Treatment of Stormwater Runoff, China Water \& Wastewater, 26(11):1-4 (2010). 